\title{
Assessing the Effect of Adulteration on Honey and Beeswax Quality and Designing Way of Identification in Oromia
}

\author{
Meseret Gemeda, Taye Negera* \\ Oromia Agricultural Research Institute, Holeta bee research center
}

\begin{abstract}
Adulteration of honey and beeswax is becoming a serious and cross cutting problem in Africa in general and in our country in particular and many methods of analysis are available to detect falsification by carrying out chemical analysis. However, in many developing countries a laboratory analyses is not always available. Therefore, the objectives of the study are to identify materials used for adulteration, characterize physical and chemical properties of adulterated honey and beeswax to develop methods of identifying adulterated hive products (honey and beeswax). The survey were conducted in 7 zone of Oromia region (Jimma, Ilu abbabora, West wollega, East wollega, East Shoa, West shoa, South West Shoa and Addis Ababa. The result show that sugar and animal tallow are the major adulterating material while, boiling of sugar with honey, direct adding of grounded or powder of sugar to the honey and melting animal tallow with wax were major adulterating way for honey and bees wax respectively, market loss, health problem, loss of customer, price reduction and loss of trust were, major problems encountered by producer due to adulteration. Solubility and viscosity of honey and breakability, uniformity and smell of beeswax were found good methods to detect adulteration of honey and beeswax at farm get or market respectively.
\end{abstract}

Keywords: Adulteration, beekeeper, beeswax, honey and physical analysis

\section{INTRODUCTION}

Beekeeping has been practiced in Ethiopia for centuries and currently the country is the largest honey producer in Africa. On a world level, Ethiopia is fourth in Beeswax and tenth in honey production (Girma Deffar 1998). However, the majority of beekeepers in the country are still use traditional hives (MOARD, 2003). In Ethiopia, honey is almost exclusively used for local consumption, and to a very large extent (80\%) for brewing of mead, locally called 'Tej'. Ethiopia produces between 24,600 and 43,000 tones of honey per year, and is one of the five biggest wax producers with an average annual export estimated at 3000 tones (EEPD, 2006). From traditional hives, an average of 5-6 kg of honey could be cropped/hive per year. However, in areas where improved technology has been introduced, yields of 15-20 kg/hive per year have been recorded. Low productivity and poor quality of bee products are the major economic impediments for beekeepers (Nuru, 1999). Honey and beeswax should be carefully handled starting from harvesting until it reaches to consumers. One of the problems of honey and beeswax quality in the country is adulteration.

Now days there is a cross cutting problem of adulteration of honey and beeswax all over the world in general and in developing countries in particular. Adulteration is becoming a serious and cross cutting problem in Africa in general and in our country in particular. This situation is greatly affecting the quality and marketing of hive products. Chemical analysis is used in many cases to detect adulteration. However as this method require expensive laboratory equipments, the service is not readily available and also this chemical analysis does not serve consumers who want to buy pure products from the market for immediate use. Therefore, this study was initiated to identify adulterant materials and simple methods to detect adulterated honey and beeswax.

\section{MATERIAL AND MeTHODS}

\subsection{Study Area}

The survey were conducted in seven zone of Oromia region ( Jimma, Ilu abbabora,West wollega, East wollega, East Shoa, West shoa, South West Shoa and Addis Ababa which were selected based on 
potentiality of honey and beeswax marketing. A total of 237 respondents were selected randomly from Beekeepers, Merchants and consumers from 14 districts and 28 kebeles of the study areas and interviewed using pre-structured questionnaire for identifying adulterant materials and to develop simple methods to detect adulterated honey and beeswax. Two hundred thirty six and six honey and beeswax samples were collected from beekeepers and merchants for identifying adulterant materials and develop simple methods to detect adulterated honey and beeswax, respectively (Table1).

Table1. Four different ratios of each bee products adulteration with different materials

\begin{tabular}{|l|l|l|l|}
\hline S.N & Product to adulterated & Source of material used for adulteration & Ratio of adulteration \\
\hline \multirow{4}{*}{} & Honey & sugar and honey & $1: 1$ \\
\cline { 3 - 4 } & & sugar and banana & $1: 1$ \\
\cline { 3 - 4 } & & Sugar, banana and honey & $1: 1: 1$ \\
\cline { 3 - 4 } & & sugar, water and honey & $2: 1: 1$ \\
\hline \multirow{4}{*}{ Wax } & beeswax and Candle & $1: 1$ \\
\cline { 3 - 4 } & beeswax and animal tallow & $1: 1$ \\
\cline { 3 - 4 } & beeswax, animal tallow and candle & $1: 2: 2$ \\
\cline { 3 - 4 } & beeswax, animal tallow and candle & $1: 1: 1$ \\
\hline
\end{tabular}

\section{RESULT AND DISCUSSION}

\subsection{Socio-economic Characteristics}

The average age of the beekeepers was $40 \pm 12.93$ years with range of 20 to 76 years. It was found that $37.9 \%$ of the beekeepers were in the age category of $31-40$ years. The remaining $24.1,20.7 \%, 12.1 \%$ and $5.2 \%$ of the beekeepers found in the age groups of 20-30, 41-50, 51-60, >60 and 51-60 years, respectively. From the total respondents about $92.2 \%$ are Male and the rest are Female Beekeepers.

Table2. Age category of the respondents

\begin{tabular}{|l|l|l|l|}
\hline Age category & Beekeepers & Merchants & Users \\
\hline$<20 \%$ & & 9.2 & \\
\hline $21-30(\%)$ & 24.1 & 33.8 & 26.8 \\
\hline $31-40(\%)$ & 37.9 & 35.4 & 17.9 \\
\hline $41-50(\%)$ & 20.7 & 15.4 & 30.4 \\
\hline $51-60(\%)$ & 12.1 & & 12.5 \\
\hline$>60(\%)$ & 5.2 & 6.2 & 12.5 \\
\hline Average age(yrs) & $40(12.93)$ & $35(11.21)$ & $41(14.53)$ \\
\hline Min age (yrs) & 20 & 17 & 22 \\
\hline Max age (yrs) & 76 & 70 & 85 \\
\hline
\end{tabular}

The study also showed that from the total respondents about $8.6 \%$ illiterate, $6.9 \%$ literate or informal school education, $23 \% 2 \%$ high school (9-12), 6.0\% not answered and 5.2 \% has College diploma. But the majority (about 50\%) of the farmers are elementary school (1-8).

The average age of the merchants was 35 years with standard deviation of 11.21. It was found that $35.4 \%$ of the merchant were in the age category of 31-40. The remaining 33.8, 15.4\%, $9.2 \%$ and 6.2 $\%$ of the merchant found in the age groups of 20-30, 41-50, <20 and >60 years, respectively. It was also observed that age of interviewed merchant ranged from 17 to 70 years. From the total respondents about $76.9 \%$ are Male and the rest are Female merchant. The study also showed that from the total respondents about $6.2 \%$ illiterate, 30.8\% high school (9-12), 24.8 elementary school $(1-8), 3.1 \%$ has certificates, and $4.6 \%$ has College diploma, $1.5 \%$ has above college diploma and 29.2 $\%$ not answered.

The average age of the users was 41 years with standard deviation 14.53 it was found that $30.4 \%$ of the users were in the age category of 41-50. The remaining $26.8,17.9 \%, 12.5 \%$ and $12.5 \%$ of the merchant found in the age groups of 20-30, 31-40, 51-60 and >60 years, respectively. It was also observed that age of interviewed merchant ranged from 22 to 85 years. From the total respondents about $57.1 \%$ are Male and the rest are Female user. The study also showed that from the total respondents about $5.4 \%$ illiterate, $35.7 \%$ high school (9-12), 41.1 elementary school (1-8), $7.1 \%$ has certificates, and $5.4 \%$ has College diploma and $1.8 \%$ has above college diploma. 


\subsection{Perception of the Respondent on the Adulteration of Honey and Bees Wax}

\subsubsection{Beekeeper}

The study showed that from the total respondents about $94 \%$ and $36 \%$ of respondents were aware of honey and bees wax adulteration, respectively. Whereas the majority of respondent claimed that adulteration of honey and beeswax is done mainly by retailers and collectors and less extent by beekeeper, wholesalers and road side sellers. About $48.3 \%$ and $9 \%$ of the consumers were had a chance of buying adulterated honey and bees-wax respectively from district and village market. According to the respondents, sugar, mixture of sugar and banana, mixture of sugar and molasses, plant roots, and candy are used to adulterate honey, while maize flour, animal tallow, paraffin, candle are the ones used to adulterate beeswax. The respondents indicated that adulteration of honey and beeswax are conducted through different ways. These includes boiling sugar with honey directly adding sugar powder to the honey melting of animal fat with wax and boiling of soap ,candle , maize powder or flex with beeswax .

$59.5 \%$ of the respondents identify adulterated honey by testing and smelling while $17.2 \%$ estimate by continues flow. But $8.6 \%$ cannot identify even though the rest can identify by using coca cola, thickness of the honey and using fire. $80.2 \%$ of the respondents cannot identify adulterated beeswax, $3.4 \%$ can identify by colour of the wax while the rest identify by smell, observation uniformity and breakability of the foundation sheet. According to the majority of respondents beekeepers reported that adulteration is done in both honey flow season $50 \%$ and also there is the price difference between the pure and the adulterated honey $83.6 \%$. The major problems caused and reported by respondents beekeepers because of adulteration are production minimization, price reduction and health problem.

\subsubsection{Merchants}

The study showed that from the total respondents about $60 \%$ and $12.3 \%$ bought adulterated honey and bees wax respectively the rest of the respondent they did not bought. According to the result from $60 \%$ of respondent bought adulterated honey the majority $27.7 \%$ one times, and list $6.2 \%$ three times and from $12.3 \%$ the majority of respondent bought adulterated bees wax $4.6 \%$ one and two times and $3.1 \%$ five and above five times .The majority respondent mention collectors $16.9 \%$, retailers $12.3 \%$ and roadside sellers $12.3 \%$ responsible for adulteration of beeswax.

The respondent mention during study the market place they bought adulterated honey and beeswax from zonal level market $13.8 \%$, farm gate $12.3 \%$ and woreda level $10.3 \%$ market and the rest is from village level and other market place. Also the respondent mention they think adulteration done in woreda level $22.4 \%$ and Village level markets $7.8 \%$ the rest done in zone town, regional and other market places.

The major adulterant material of honey are sugar $69.2 \%$, candy and sugar with molasses $6.2 \%$ the rest adulterant materials is sugar with banana, orange and cumber and the list adulterating material mentioned by respondents are Soil and stone $1.5 \%$ while $3 \%$ they did not know the material . $21.5 \%$ of respondent they did not identify the adulterating but the major adulterating mentioned are animal tallow 20\% the rest was animal tallow with candle, lime stone maize flex or powder $.21 .5 \%$ cannot identify adulterated honey and $7.7 \%$ not answered some of the respondent can identify by test $21.5 \%$ the rest identify by observation, smell, by firing, using coca cola the list identification mention by certification of the honey. Majority of them $86.2 \%$ cannot identify adulterated beeswax the rest identify by colour, smell and breakability of the wax.

The respondent report that they get pure honey or bees wax from common customer or one beekeeper $66.2 \%$ and certification and common trust is the list way mentioned during the marketing process $53.3 \%$ the merchant allow the user to test honey or wax before they bought to get the trust from the user. $43 \%$ of them sells their honey and bees wax in the market by common trust or believe and only $3 \%$ of them sells certified and packed honey.

According to the result majority of respondents they do not knew how adulteration is done $64.6 \%$ and $33.8 \%$ honey and beeswax respectively but boiling of sugar and adding to honey $36.9 \%$ and melting of animal tallow with wax $10.8 \%$ is the major ways of adulterating honey and wax respectively $43 \%$ of them sells their honey and bees wax in the market by common trust or believe and only $3 \%$ of them sells certified and packed honey. 
Adding soil to honey is the list adulterating ways of honey by merchant, adulteration is done in both seasons according to the respondents. Majority of the respondent report there is a price difference between the pure and the adulterated one and market loss, price reduction and health problems are major problems mentioned.

\subsubsection{Users}

According to the result the majority of respondent mentions that $16.1 \%$ road side seller and collectors $16.1 \%$ major responsible also beekeeper is mentioned $8.7 \%$ for adulteration of honey and beeswax while rest done by other actors in the market like, wholesalers and retailers and the users think adulteration is majorly done zone town market, woreda town market and farm gate $32.1 \%$, $21.4 \%$ and $17.9 \%$ respectively the rest is done in village and regional level markets.

Direct adding of crushed or powder of sugar $28.6 \%$ and boiling of sugar $25 \%$ adulterating with honey is the major ways of adulterating honey and $96.3 \%$ respondents report that they do not know how adulteration of wax is done.

Sugar is the major adulterating material $69.6 \%$, other is mix of sugar with banana, molasses and irid (local name) was used us adulterating materials for honey and majority of the respondent do not know bees wax adulterating materials $96.3 \%$. According to the result users respondents reported that the identification method of the pure and adulterated honey the major is by test $46.4 \%$ and smell $10.7 \%$ and the list identification method reported is using fire and coca cola. Majority of the respondent $98.2 \%$ cannot identify adulterated bees wax .the majority was agreed there is price difference between the pure and the adulterated one. Problem encountered because of adulteration list by the respondent majorly loss of satisfaction, health problem and loss value of the product.

\subsection{Laboratory Analysis}

Samples of $1 \mathrm{~kg}$ of honey and beeswax each collected from producer and merchant from different zone of each study areas (both market spot and on farm gates). The physical properties or organolephetic test for honey was done in HBRC laboratory but chemical properties test were not done because any standard laboratory found in our country not done any test for honey currently. The physical and chemical property of the collected beeswax and adulterated beeswax prepared by different ration from two adulterating material was analyzed at HBRC and ECAE laboratory. In this study, adulterated beeswax prepared the value obtained from melting point, saponification clouding point, refractive index, ash, $\%$ by mass, total Volatile matter, acid value and eater values were not fulfil in the required standard values of $61-66^{\circ} \mathrm{C}, 85-105,1.4400-1.4450,0.22 \mathrm{max}, 0.75 \mathrm{max}, 17-24$ and 70-80 respectively according to Ethiopian Conformity Assessment Enterprise (ECAE) laboratory.

\subsection{Physical Property Adulterated Beeswax}

Bees wax with both animal tallow and candle with equal amount of them and fewer amounts the pure bees wax have smell of animal tallow, light yellow in colour, appearance not uniform inside and, easily or smoothly breakable Adulterated beeswax with candle only and equal amount it have uniform appearance, yellow in colour, breakage is like bees wax, goodsmell.

Adulterated beeswax with animal tallow only and equal amount have tallow smell, dark yellow colour, smoothly breakable and appearance it seems like bees wax. Adulterated beeswax with equal amount of animal tallow and candle and pure bees wax have light yellow colour ,smoothly breakable, tallow smell and appearance is not like bees wax .

\subsection{Physical Property of Adulterated Honey}

Adulterated honey with arid local name, this adulteration changes the colour of the honey into yellow. Adulterated honey with, sugar, honey and water by using heat means by boiling it have light white in colour; test is sweet like sugar, very liquid, look like pure honey but the sugar settle at the bottom of the honey container. Adulterated honey with equal amount honey with sugar melting of sugar it have red colour and it becomes solid adulterated white honey with sugar by directly adding, have extra white colour and ferment it look like pure honey by necked eye, Adulterated honey with molasses using heat it have black colour looks like honey coffee honey colour. Adulterated honey with banana at the bottom it is in the liquid from and in the upper layer it forms yeast. All the adulterated honey does not fulfil standard honey moisture content quality parameter. Physical test were done for honey sample collected according to the perception of the respondents on the physical 
identification of the adulterated honey during the test the control group also checked by those identification test method for the control group we used pure honey harvested from HBRC, pure also shows adulteration in different identification test methods shows adulteration from this one is in coca cola test method this may be from the content of coca cola and honey which causes fermentation during mixing the two of the them or the time the honey were harvested until the test is undertaken. Another test method observation done for adulteration detection is how liquid honey comes down into a glass of water. Pure honey does not immediately dissolve in water you will notice that it takes a bit of effort to stir it in the water to dissolve, whereas sugar tends to dissolve easily as you drop them into the water. However, test result is sometimes not that clear because different honey varieties have different viscosity. Some are denser and thicker than others. Obviously, honey in cream form, even if it's adulterated with other substance, will not dissolve as easy as liquid honey in water. In the rest of the identification methods, it shows purity of the control honey according to the precaution of the respondents.

Generally, all respondents answered that sugar is the major honey adulterating material, while majority of them do not know adulterating materials of bees wax.

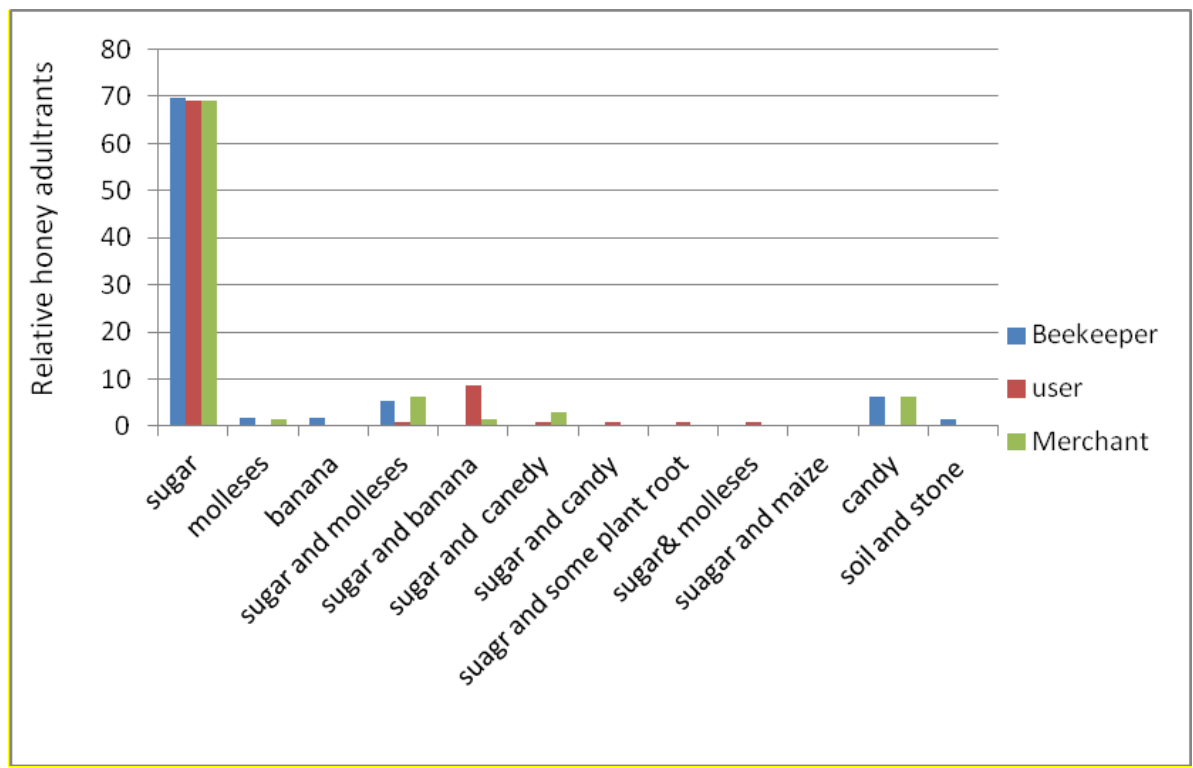

Graph1. Honey adulterating materials

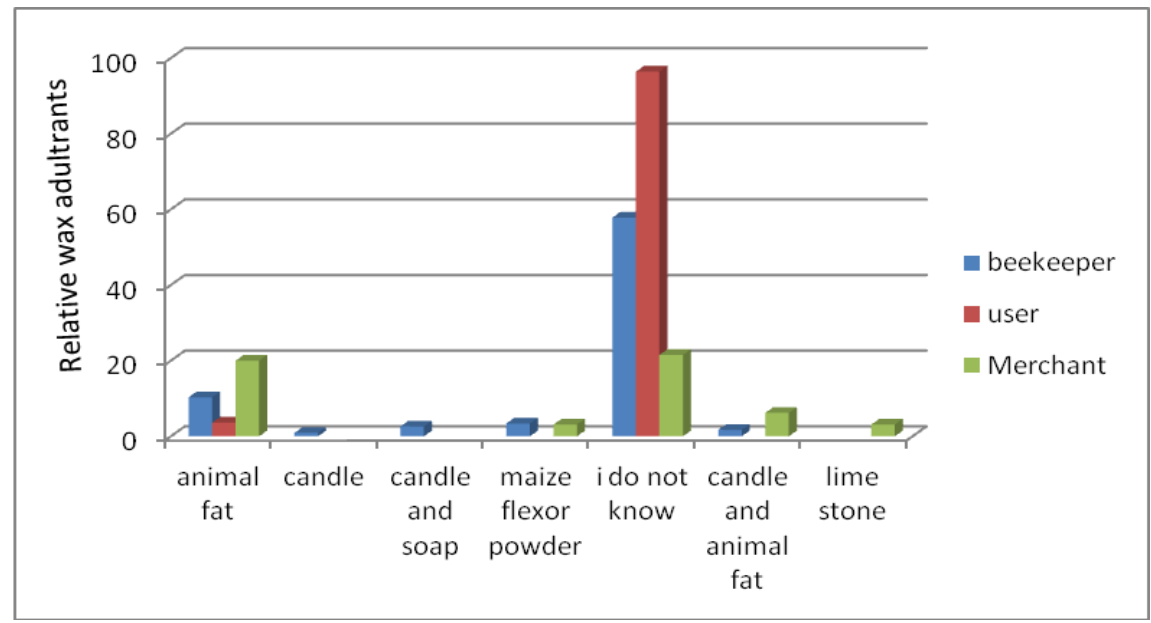

Graph2. Adultrating material of bees wax

\section{CONCLUSION AND RECOMMENDATION}

Sugar and animal tallow is the major adulterating material boiling of sugar with honey, direct adding of crushed or powder of sugar to the honey and melting animal tallow with wax major adulterating way for honey and bees wax respectively. Market loss, health problem, loss of customer, price reduction and loss of satisfaction are major problems caused due to adulteration. Dissolving in the 
water and continues flow show good result for the physical identification methods of adulterated honey while breakability, uniformity and smell are concluded as physical identification methods of adulterated beeswax. The information delivered from this work should be disseminated to the concerned body and further study on the techniques and procedures used to detect or physical identification of honey and bees wax adulteration is recommended.

\section{REFERENCES}

[1] Bogdanov S, et al. (1999) Honey quality, methods of analysis and international regulatory standards: review of the work of the International honey comission, Mitt. Lebensm.

[2] Girma Deffar 1998 Non-Wood Forest Production in Ethiopia. Addis Ababa,Ethiopia http:// www.fao.org/DOCREP/003/X6690E/X6690E00.htm

[3] EEPD (Ethiopian Export Promotion Department). 2006. Exports of honey and beeswax. Draft report. EEPD, Ministry of Trade and Industry, Addis Ababa, Ethiopia.

[4] Nuru Adgaba. 1999. Quality state of grading Ethiopian honey. In: Proceedings of the fi rst national conference of the Ethiopian Beekeepers Association, Addis Ababa, Ethiopia.

[5] Amsalu B, Nuru A, Radloff SE and Hepburn HR. 2004. Multivariate morphometeric analysis of honeybees in the Ethiopian region.

[6] Joseph, T., Awah-Ndukum, J., Fonteh-Florence, A., Delphine, N. D., Jonnas, P. and Ze Antoine, M. 2007. Physico-chemical and microbiological characteristics of honey from the SudanoGuinean Zone of west Cameron. African Journal of Biotechnology.

[7] CSA (2012). Central statistical agency, Addis Ababa, Ethiopia.

[8] ECRA(2010).Ethiopian Custom and Revenue Authority Addis Ababa, Ethiopia

[9] Gemechis Legesse Yadeta (2014).Beeswax Production and Marketing in Ethiopia: Challenges in Value Chain. Agriculture, Forestry and Fisheries. Vol. 3, No. 6, 2014, pp. 447-451. doi: 10.11648/j.aff.20140306.12

[10] SPDGCHIE, (2015), Strategic Plan to Develop Globally Competitive honey Industry in Addis Ababa, Ethiopia.

[11] Nuru, Adgaba (2000). Physical and chemical properties of Ethiopian bees-wax and detection of its adulteration .Ethiopian J, Ani.Pro7; 39-48.

[12] Nuru, A. and Eddessa, N. (2006). Profitability of processing crude honey. Pp 79-84. Proceedings of 13th Annual Conference of Ethiopian Society of Animal production (ESAP). August 25-27, 2004. Addis Ababa, Ethiopia 244pp

Citation: M. Gemeda, "Assessing the Effect of Adulteration on Honey and Beeswax Quality and Designing Way of Identification in Oromia", International Journal of Research Studies in Biosciences (IJRSB), vol. 5, no. 8, p. 39, 2017. http://dx.doi.org/10.20431/2349-0365.0508006

Copyright: (C) 2017 Authors. This is an open-access article distributed under the terms of the Creative Commons Attribution License, which permits unrestricted use, distribution, and reproduction in any medium, provided the original author and source are credited. 